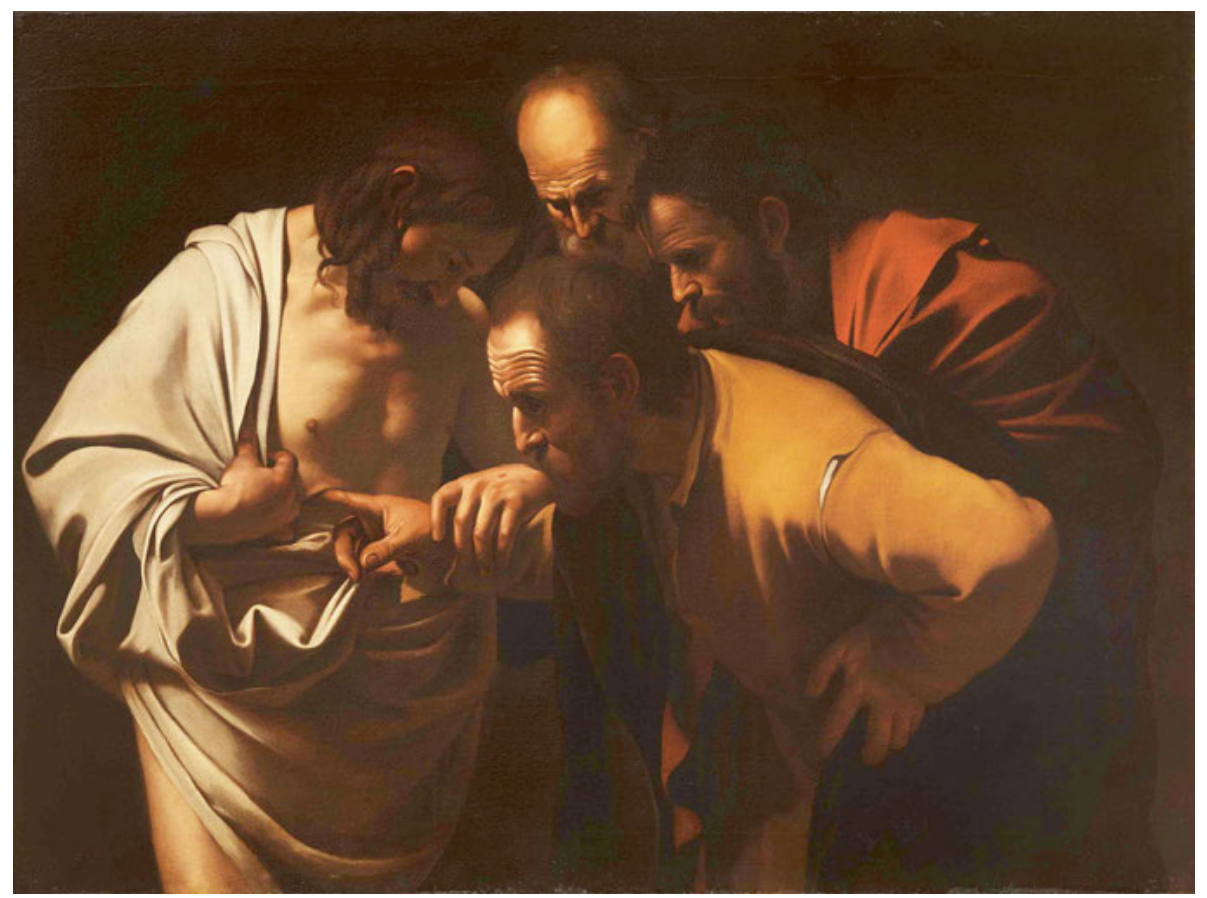

Fig. 10: Caravaggio, The Incredulity of Saint Thomas, 1601-1603, oil on canvas, $107 \times 146 \mathrm{~cm}$., Sanssouci Picture Gallery, Potsdam, Germany. Image Source: Heritage Images. 


\section{Touching Doubt: Haptolinguistic Scepticism}

The purpose of this contribution is to address the problem of touch and doubt through a much broader question of the relation between touch and language. What I would like to do is to contrast touch with doubt as a conceptual and linguistic activity.

To illustrate this approach, let me first begin with two of the most intriguingly consecutive passages from the New Testament. In the first, the resurrected Jesus Christ stops his pupil Mary Magdalene from touching him with his famous command noli me tangere, while in the second, which is an almost perfect reversal of this scene, another of Christ's pupils, "Doubting" Thomas, places his finger inside the wounds of his resurrected body. Both scenes evoke contradictory tendencies with regard to touch that require further discussion. In the first passage, the desire to dissolve doubt through touch is stopped by a gesture that itself pertains to the domain of touch. The gesture is complemented by the sentence "do not touch me," which not only provides certainty, but also demonstrates the peculiar relationship between touch and language. In the second passage, the discursive doubt articulated by Thomas's questioning of the resurrected body of Christ is shattered through a silent, speechless, penetrating touch: certainty achieved at a fingertip.

Due to their dramatic nature, it is no coincidence that both scenes can be found in religious iconography, Renaissance paintings, and later even in popular culture (in the form of music, musicals, and films). They appear not only as paradigmatic representations of faith and doubt colliding with the realm of the senses, but also as allegorical representations of a certain fragility of sense-certainty. In both instances, we can see a linguistic implosion of the sense of touch, itself embodying, so to speak, a challenge to the traditional philosophical pairing of the more theoretical senses of sight and hearing. In this regard, it is telling that the first example has taken on a name of its own: contemporary usages of noli me tangere are similar to the Last Supper or the Crucifixion of Christ in the sense that it has acquired an almost independent secular currency, addressing certain tactile issues that were present long before-such as, for instance, and perhaps most famously, in Sophocles's Oedipus in Colonus, where Oedipus, just before his apotheosis, addresses his daughters Antigone and Ismene in the same vein in which Jesus addresses Mary Magdalene; namely, with the words "Follow me, but do not touch me."1

I will return to the noli me tangere scene with Mary Magdalene soon (contrasting it with the touch of Doubting Thomas), but for now, let me lay out the most general theoretical layout of my contribution: that the exploration of the mutual relation and interaction between the two triads of sight-hearing-touching and doubt-certainty-

1 Sophocles, The Three Theban Plays (London: Penguin Classics, 2008).

https://doi.org/10.1515/9783110627176-008 
faith in these two scenes-as theoretically advanced by Jean-Luc Nancy in his own Noli me tangere ${ }^{2}$-allows us to move from a strictly phenomenological understanding of touch as a sensorial activity of the body, and the related understanding of doubt as a discursive activity of the mind, towards a linguistic conception of touch that is epistemologically grounded in Hegel's philosophy and further developed by Lacanian theoretical psychoanalysis.

In a different context, I proposed calling this approach "haptolinguistics,"3 which can presently help us to navigate through the Scylla of Touch and the Charybdis of Doubt as follows. In the first part of this contribution, I will address the question of doubt through the age-old mind-and-body problem in Plato-by employing Saussurian linguistics as developed within the theoretical framework(s) of Lacan, Derrida, and Nancy-in order to tackle the metaphysical dimension of touch on the one hand and its metaphorical aspect on the other. In part 2, I will once more address the mind-and-body issue of doubt through linguistics, focusing on Aristotle's theory of the soul, through which I intend to introduce the metonymy of touch as opposed to its metaphor. In part 3, I will lean heavily on Hegel in order to develop the linguistic perspective even further, from touch understood as a bodily activity that can be the source of doubt, via the metaphor of touch, towards touch as concept, or Begriff, that operates on the same level as doubt. Finally, in part 4, I will employ Lacan's theory of knots in connection to his concept of lalangue in order to demonstrate how language, the site of doubt, possesses a certain tactile quality in itself. My thesis is, in short, that doubting touch and the touch of doubt are two sides of the same object and that doubt itself is a linguistic effect, which touches upon the subject-literally, materialistically-due to a certain haptic quality of language.

\section{A Doubt of Sense-Certainty}

Now, let me re-begin at the very beginning of philosophy, with Plato, whose main philosophical concern was to dismiss the realm of the senses and point-as depicted in the famous fresco La Scuola di Atene by Raphael-to the higher, transcendental, untouchable realm of ideas.

Despite the fact that Plato, among others, despised the senses as a source of erroneous falsehood, we could, in contrast, also list an entire array of Platonic metaphors that describe the abilities of the soul using images taken from the realm of bodily perception, from which one could discern that metaphors of the gaze and the voice are central in the metaphysical imagery that structured most post-Platonic

2 Jean-Luc Nancy, Noli me tangere: Essai sur la levée du corps (Paris: Bayard, 2003).

3 See my chapter entitled "The Wave of the Sign: Pyramidal Sign, Haptic Hieroglyphs, and the Touch of Language," in The Language of Touch: Philosophical Examinations in Linguistics and Haptic Studies, ed. Mirt Komel (London: Bloomsbury, 2019), 5-18. 
philosophy. ${ }^{4}$ The predominant metaphors still in use in present-day philosophy are optical; that is, related to sight and visuals ("theory," "gazing," "insight," "speculation," "reflection"). Closely following in frequency are acoustic metaphors related to the voice, hearing, and obedience in the sense of "listening to" (from the ethics of the Socratic daimon to the morality of the Christian conscience). Smell and taste have, curiously enough, for the most part been deemed unsuitable for expressing spirituality. Finally, the sense of touch appears both as a paradigm of the most basic sensual body and as the supreme metaphor of one's spiritual contact with metaphysical reality. ${ }^{5}$

If we focus on the sense of touch and its metaphorical equivalent on the level of the soul touching the realm of ideas, we can see that in Plato's Phaedo, there is a strict mutual exclusion between the two: if a soul wants to grasp ideas, it has to renounce the concept of bodily touch as a link to reality. To gain one kind of touch, we have to rid ourselves of the other (hence the stereotypical depiction of philosophers as wisdom-seekers who are, however, completely lacking a worldly-wise "grasp" of reality). This radical Platonic gesture makes touch, as the guarantee of empirical sense-certainty, something that needs to be renounced in order for it to function as the privileged metaphor of metaphysical knowledge. In this, we can see the foundations of what Jacques Derrida calls the "haptocentrism of the Western metaphysical tradition" in his On Touching-Jean-Luc Nancy, always already privileging the hands, palms, fingers-in short, touch-in order to affirm the presence of the subject: "Such a hierarchical arrangement is without any doubt part of the great tradition that accords an absolute privilege to touch and does not let itself be encroached upon by the possibility [...] of any vicariousness of the senses." ${ }^{\prime 6}$ As we can see, this thesis largely concords with his other, earlier thesis on "phonocentrism" in linguistics and philosophy, and therefore, both should be read together: the voice on the one hand and touch on the other create or allow an illusion of a self-conscious presence of the subject.

\footnotetext{
4 Numerous studies have dealt with the role of metaphor in metaphysics (see Stephen C. Pepper, World Hypotheses [Berkeley: California University Press, 1942]; Charles Morris, Paths of Life: Preface to a World Religion [New York: Harper and Brothers, 1942]), which, however, assign it only a didactic, explanatory function, and merely an aesthetic one in literature. This is questionable on several counts; for one, it would be easy to demonstrate the didactic value of poetry, and, at the same time, the aesthetic value of philosophy. For perhaps the best examination of this issue, see Jacques Derrida, "White Mythology: Metaphor in the Text of Philosophy," in Jacques Derrida, Margins of Philosophy, trans. Alan Bass (Chicago: University Press, 1982), 207-71.

5 The persistence of such a hierarchy of the senses can be followed as far as Hegel, who faithfully reproduces it on many occasions: for instance, in his Lectures on Aesthetics, where the division of artforms into visual and acoustic categories is based on the distinction between sight and hearing as theoretical senses on the one hand and touch, smell, and taste as non-theoretical and non-artistic senses on the other (see Georg Wilhelm Friedrich Hegel, Aesthetics: Lectures on Fine Art, Volume One, trans. T.M. Knox, paperback ed. [Oxford: Clarendon Press, 1988], 622-23).
}

6 Jacques Derrida, Le toucher, Jean-Luc Nancy (Paris: Galilée, 2000), 41. 
Jean-Luc Nancy, to whom On Touching is dedicated, answered Derrida in a peculiar way with his own formulation of noli me tangere. It is here, Nancy argues, within the framework of his own project of a "deconstruction of Christianity," that such a tradition of haptocentrism is most illustratively expounded in the comparison between the two scenes from the New Testament mentioned above: on the one hand, there is the scene of the proverbial Doubting Thomas touching Jesus's wound in order to empirically verify the evidence provided by his eyes and ears, while on the other, there is the scene of the resurrection in which Jesus appears to Mary Magdalene and does not permit her to touch him, but rather demands a leap of faith: "Faith consists in seeing and hearing where there is nothing exceptional for the ordinary eye and ear. It knows to see and to hear without tampering."7 Faith demands belief without tactile corroboration, for it is precisely touch-with its direct tactility-that expunges the truth, which is by definition something intangible. The opposition here runs between the untouchable and the touchable, the realm of the intangible and the realm of the tangible, with touch itself marking the dividing line. This is why Nancy can say that noli me tangere expresses something that revolves around touch in general, something that "touches on the sensitive point of touching" (elle touche au point sensible du toucher), "on this sensitive point that touching constitutes par excellence" and "forms the sensitive point within it." Sensibility from the realm of the touchable and sense from the regime of the untouchable coincide in touch as the sense of sensibility: in short, sensibility can make sense only if one presupposes the sense of tact, which is the condition sine qua non for a sensorial being-without touch, no other sense is possible. And that is why, in contrast and conversely at the same time, the sensibility of sense makes sense, or, in one French word, sens, which is Nancy's favorite play on words in which "sense" is in linguistic accordance with sensibility (since sens does not mean either/or, but rather both at the same time: the bodily activity of sensing and the thinking activity of making sense).

If we translate Nancy's language-based play into the modern linguistic Saussurian formula of the sign, S/s (signifier/signified), ${ }^{9}$ then noli me tangere is precisely the bar (/) that separates the level of the untouchable signifier (S) from the level of the tangible to which the signified (s) refers on the one hand, while on the other, the signifier/signified compound enables the contact between the two levels insofar as it touches both. ${ }^{10}$ The negative imperative "do not touch me" is something that impos-

7 Nancy, Noli me tangere, 22.

8 Nancy, 13.

9 See Ferdinand de Saussure, Course in General Linguistics, ed. Charles Bally and Albert Sechehaye in collaboration with Albert Riedlinger, trans. Wade Baskin, 3rd ed. (New York, Toronto, and London: McGraw-Hill, 1966).

10 A further elaboration of such a haptolinguistic conception of the Saussurian sign through the concept of (un)touchability can be found in Bara Kolenc's "The Category of the (Un)touchable in Haptic Materialism: Touch, Repetition, and Language” in the above-mentioned The Language of Touch, 91- 
es touch as such on both the signifier and signified ("touch" in this context meaning both the imperative phrase and the bodily activity), while, as a distinguishing bar (/) between signifier and signified, it touches both at the same time.

If we translate the Saussurian formula into the Lacanian categorial apparatus, we can see how the untouchable level of the signifier corresponds to the symbolic register, the tangible level of the signified to the imaginary, and the role of the bar to the real inasmuch it resists and defies any symbolic and/or imaginary appropriation. ${ }^{11}$ Moreover, what enables the transition between the symbolic and the imaginary can be grasped via the Lacanian formula of the metaphor, according to which it is in the substitution of signifier for signifier- "one word for another," be it "poetic or creative"-that a "signification effect is produced," while the crossing of the bar has a "constitutive value [...] for the emergence of signification." 12 The "word for word" of the metaphor, the displacement of meaning that happens when we use a metaphor instead of the "proper" word, is, in our case, the replacement of the physical touch by the metaphysical touch of the soul; through the metaphor of the "touch of the soul," a certain crossing of the distinguishing bar (/) in the haptic division between the tangible and the intangible takes place. Or, to put it more simply, translating the Lacanian idiom back into the Platonic terms with which we began this section: the metaphor of touch allows a smooth transition between the republic of intangible ideas, identified with the linguistic "upper house" of signifiers, and that of tangible bodies, broadly coinciding with the "lower house" of the signified.

\section{A Touch of Heart and Soul}

In order to take a step forward, we need to make a step back: speaking in terms of the bodily senses and their metaphorical equivalents on the level of the soul presupposes an existing distinction between body and soul, the traditional bread and butter of philosophy from Plato to Hegel.

Seen from the ancient Greek perspective, the division between body and soul originates in the pre-Socratic Homeric imagery, in which psyche is used primarily as a synonym for $z \bar{o} \bar{e}$, "life" or "aliveness," after whose removal there remains

106: the elegance of the concept of (un)touchability lies in its speculative unity of touchability and untouchability, thus allowing us to think the very concept of sign as itself unmaterial, to be sure, but as capable of producing material effects on the body.

11 In Lacanian theoretical psychoanalysis, the three registers of symbolic, imaginary, and real encompass the whole of human existence through the experience of language (symbolic), the bodily senses and the empirical representations they provide (imaginary), and the real that defies both by being irreducible to either language or the senses and thus being exclusively graspable through science, understood as the science of the sign, or rather, the letter (Jacques Lacan, Le séminaire, livre XXIII: Le sinthome, 1975-76, ed. Jacques-Alain Miller [Paris: Éditions de Seuil, 2005]; Jean-Claude Milner, Le périple structural: Figures et paradigme [Paris: Éditions du Seuil, 2002]).

12 Jacques Lacan, Écrits (Paris: Éditions de Seuil, 1966), 429. 
only sōma, which in Ancient Greek does not mean "body," but "corpse” (whence the Homeric formula that sōma is $z \bar{o} \bar{e}$ minus psyche $) ;{ }^{13}$ only in the context of metaphor does psychē appear as a soul that wanders around in dreams and, in the afterworld, lives merely a reflection of its past life on earth (psyche as a soul living a life independently of the body). ${ }^{14}$ The original incision separating spiritual intangibility from bodily tangibility is therefore metaphorical, which is also why it should come as no surprise that metaphors are omnipresent whenever and wherever there is talk of metaphysical entities as autonomous beings (soul, ideas, etc.).

This is perhaps why the resurrection of Christ invokes-to put it bluntly-so many doubts concerning his body. The body of Christ is simultaneously elevated and degraded in a curious paradox of touch and doubt, as best exemplified precisely in both scenes of interest to us here: in Mary Magdalene's noli me tangere scene, the body is inadequate, since it cannot provide the certainty that only faith can supply; in the Doubting Thomas scene, the same resurrected body functions as the ultimate confirmation of faith itself. However, as Hegel argued at the very beginning of his philosophical career, "Contradictio est regula veri, non contradictio falsi" ("Contradiction is the rule of truth, non-contradiction of error"). ${ }^{15}$ The paradox of the body of the resurrected Christ is a sign of truth, a certain truth of touch, since Christ's body is at the same time touchable and untouchable, as both scenes from the New Testament clearly show. And yet, the truth of the resurrected body cannot be grasped without the aid of its counterpart in the sphere of language: in the Mary Magdalene

13 At the beginning of The Iliad, we read: "The rage of Achilles-sing it now, goddess, sing through me the deadly rage that caused the Achaeans such grief and hurled down to Hades the souls of so many fighters, leaving their naked flesh to be eaten by dogs and carrion birds, as the will of Zeus was accomplished" (Homer, The Iliad [Clayton, DE: Prestwick House, 2011], 1 [verses 1-5]).

14 In The Odyssey, in the scene when Odysseus meets his mother during his journey to the realm of shades and back, we read: "Ah, my poor child, ill-fated above all mortals, this is no phantom Perséphonē sent up to meet you; it is just what happens to mortals after they die. The sinews don't hold the flesh and the bones together. When fire consumes the body and burns it to ash, the spirit slips out and flutters away like a dream" (Homer, The Odyssey, trans. Stephen Mitchell [New York: Atria Books, 2013], 143 [verses 216-22]).

15 See Hegel's doctoral thesis from 1801: "1. Contradictio est regula veri, non contradictio falsi. 2. Syllogismus est principium Idealismi. 3. Quadratum est lex naturae, triangulum mentis. 4. In Arithmetica vera nec additioni nisi unitatis ad dyadem, nec subtractioni nisi dyadis a triade neque triadi ut summae, neque unitati ut differentiae est locus. 5. Ut magnes est vectis naturalis, ita gravitas planetarum in solem pendulum naturale. 6. Idea est synthesis infiniti et finiti et philosophia omnis est in ideis. 7. Philosophia critica caret ideis et imperfecta est Scepticismi forma. 8. Materia postulati rationis, quod philosophia critica exhibet, eam ipsam philosophiam destruit, et principium est Spinozismi. 9. Status naturae non est iniustus et eam ob causam ex illo exeundum. 10. Principium scientiae moralis est reverentia fato habenda. 11.Virtus innocentiam tum agendi tum patiendi excludit. 12. Moralitas omnibus numeris absoluta virtuti repugnant” (Georg Wilhelm Friedrich Hegel, Frühe Schriften, vol. 1 of Werke, ed. Eva Moldenhauer and Karl Markus Michel, new ed. [Frankfurt: Suhrkamp, 1986], 533). 
scene, it can be discerned from the very phrase "do not touch me"; in the Doubting Thomas scene, from Jesus's invitation "touch me."

In this regard, I would like to advance another thesis that can now clarify the above-mentioned reference to Lacan's theory of metaphors via Plato; namely, that the connection between the metaphysical and natural worlds is metaphorical, which is why it is in the field of metaphors that one world unimpededly passes into the other. The metaphysical and physical worlds come into contact-in both the literal and the metaphorical sense of touch-insofar as touch is the bar that separates one level from the other and, at the same time, enables contact between them on condition that it begins to function as a metaphor.

Aristotle in De anima is the principal philosopher who, after Plato, attempted to reintegrate the soul into the body so that psyche would again become the principle expressing the life of the body (in contrast to the Homeric formula, Aristotle's goes like this: $z \bar{o} \bar{e}$ is sōma plus psychē). Instead of metaphors of touch, what we come across in Aristotle is its metonymic function: by localising the sense of touch, the medium of touching extends from the heart to the flesh, from the body to the world. Every sense has its medium of perception: sight has light, sound and smell have air; only touch-including the haptic sense of taste-according to Aristotle, does not have its specific medium. The medium of touch remains "unnoticed, unclear, hidden." ${ }^{16}$ More precisely, in the case of touch, the problem is that the sense and the medium are, on the one hand, joined in what he calls flesh, sarx. Sarx differs from the body as sōma precisely because the latter is a living body, something that relates to $z \bar{o} \bar{e}$ through $p s y c h \bar{e}$ as something that is animated. ${ }^{17}$ On the other hand, sarx or flesh is merely a medium, while the real organ of touch, again, is located even further inward: "Flesh is 'the medium' of touch, the real organ being situated farther inward." 18 The one element which is more internal to the body than flesh, and actually most internal and intimate in the final analysis, proves to be the heart: "This explains why the sensory organ of both touch and taste is closely related to the heart. For the heart as being the hottest of all the bodily parts, is the counterpoise of the brain." 19 Thus, we do not touch with our hands or fingers, but rather with our hearts. This Aristotelian "touch of the heart" is just a step away from the Platonic "touch of the soul."

However, regarding both Plato's and Aristotle's metaphorical usages of "touch,” it can also be argued that the "touch of the soul" and the "touch of the heart" are not metaphors at all, but rather something that we can infer by subsuming all the other senses under the sense of touch, insofar as all the senses are merely forms of touching at a distance, which makes the sense of touch the haptocentric paradigm of sensing in general, metonymically extending-quite literally-from the heart and soul to

16 Aristotle, Complete Works (Princeton: Princeton University Press, 1984): 423b4.

17 Aristotle, 423b17.

18 Aristotle, 422b18.

19 Aristotle, 439a1-2. 
the world. The best articulation in this regard can perhaps be found in Maurice Merleau-Ponty, who developed sarx into la chair du monde, "the flesh of the world," which is at the same time "my flesh."20 The expression indicates, in one stroke, the intertwinement of the internal and the external so that "nothing determines me from outside," but "not because nothing acts upon me, but, on the contrary, because I am from the start outside myself and open to the world." ${ }^{21}$ The flesh of the world, which is at the same time my flesh, is presupposed by the a priori equation of the internal and the external, which is why, in Merleau-Ponty, the tangible-intangible pair is equated with the visible-invisible pair, yet the very concept of the "flesh" constantly refers to a specific tactile transitivity of touch itself.

On the one hand, we have the Aristotelian transitivity of touch extending from the internal heart to the outer world, where one could add that this "inner touch" has its counterpart in the metonymical sliding under the bar from one signified (the heart) to the other (the world), from the realm of the soul towards a soul-less, or at least heart-less world. On the other hand, as we have seen, we have the Platonic imagery of touch functioning as an incision establishing the borderline between the tangible and the intangible. As Mladen Dolar writes: "The touch includes both metaphor-basically the cut-and metonymy-basically endless transitivity."22 Touch is thus an intersection of the metaphorical and the metonymical, both a metaphorical separating cut between the tangible and the intangible and, at the same time, a metonymic passing or sliding that operates on both levels. ${ }^{23}$

Thus, the Aristotelian metonymic touch slides along the axis of the signified as a reference to the realm of the tangible, while the Platonic metaphorical touch slides along the signifying axis into the regime of the intangible. We now need to consider both as two sides of the same "object-touch" that functions as a binding and splitting gap between the sensible order of the tangible and the transcendental order of the intangible world, since it is precisely here that doubt collides with sense-certainty - "sense" in both meanings of the word, noumenal and phenomenal.

20 Maurice Merleau-Ponty, The Visible and the Invisible; Working Notes, ed. Claude Lefort, trans. Alphonso Lingis (Evanston, IL: Northwestern University Press, 1968), 250.

21 Maurice Merleau-Ponty, Phenomenology of Perception, trans. Colin Smith, new ed. (New York and London: Routledge, 2002), 530.

22 Mladen Dolar, “Touching Ground,” Filozofski vestnik 29, no. 2 (2008): 95.

23 For a beautiful demonstration of one such operation in different terms-but in a not so different context from this one-see Rachel Aumiller's "The Lick of the Mother Tongue: Derrida's Fantasies of 'the Touch of Language' with Augustine and Marx," in The Language of Touch, 107-20: the "lick of the mother tongue" can be understood as the metaphorical "cut" that produces a schism in the subject by installing the intangible regime of the signifier as something different and opposed to the tangible body, while at the same time it metonymically allows the transition from one level to the other precisely by means of "touching" us-"licking us," in fact-thus producing real, material, tangible effects. 


\section{A Begriff of Touch and Language}

Arguably, one of the best treatments of touch as a crossroads between the phenomenal and the noumenal is given by Hegel in his Lectures on Aesthetics, which presents the idea of beauty as a self-development of the spirit in the sphere of freedom that is pertinent to the fine arts, or, in the more telling Italian version, belle arti. ${ }^{24}$

If touch is taken as the criterion of Hegel's self-development of the spirit, we could say that the idea in general is intangible, while its objectification and concretisation essentially constitute its tactilisation, a means of making an idea palpable. However, as Hegel himself says a little later on, at the end of the introduction to the chapter on "The Idea of the Beauty of Art or the Ideal," from the perspective of the finitude of the spirit, the absolute looks like "an infinite object standing against it." Yet when looked at "from the higher speculative way, [spirit] is the absolute spirit itself" that "makes these distinctions within itself" and thus establishes the "finitude of spirit, within which it becomes the absolute object of the knowledge of itself," which is why "the realm of fine art is the realm of the absolute spirit." ${ }^{25}$ What looks like a distinction between touchable works of art and an untouchable idea of beauty as such-with the ideal being correspondence between the two-is actually (this is to say, speculatively) a distinction made within the absolute spirit itself.

The same logic applies to Hegel's “concept of concept," elegantly introduced at the beginning of the next chapter entitled "The Concept of Beauty in General." Hegel recapitulates his definition of "beauty as the idea of beauty," meaning that "beauty must be conceived as idea," and even more precisely, "as idea in a determined form, as ideal." He goes on to define "the idea in general" as nothing less than the "concept, the reality of the concept, and the unity of both." ${ }^{26}$ Again, from the perspective of touch and doubt, the concept that is the means through which doubt drills into the certainty of the body would fall into the category of untouchable, while the reality to which it relates would fall into the category of the touchable and palpable: each finds its speculative unity in merely abstract definitions of the idea, which should, however, not be understood as neutralising the peculiarities of each of these aspects, of the concept and its reality, of the intangibility of the concept as the source of doubt and the palpability of bodily reality respectively. On the contrary, this unity

24 It is important to note that here, the idea of the beauty of art does not correspond to the idea as such, since the latter is apprehended as the absolute truth, universal, yet not yet objectified, while the former is defined as the beautiful objectification of the idea, "both essentially individual reality and also an individual configuration of reality destined essentially to embody and reveal the Idea"; implicitly present in such an understanding is a "demand that the Idea and its configuration as a concrete reality shall be made completely adequate to one another," which is precisely the definition of the ideal as the concordance between the very "concept of the idea" and its "reality" (Hegel, Aesthetics: Lectures on Fine Art, 73-74).

25 Hegel, 93-94.

26 Hegel, 106. 
is itself conceptual in the sense that the distinction is made within the concept itself, and its realisation is actually self-realisation.

The same Hegelian speculative turn can be applied to the concept of touch: the difference between the touchable and the untouchable is pertinent to the concept of touch itself, since it is the instance of touch that differentiates between the touchable and the untouchable (touch being the criterion according to which one can think in either/or touchable/untouchable terms). Although the consideration of the development of the idea of beauty from the perspective of touch is not pertinent to Hegel's own accounts, if we fast-forward a few hundred pages into his Aesthetics, we can see that touch eventually-and, I would like to add, both accidentally and inevitablypops up in relation to the "concept of concept" in a very peculiar way.

In the section entitled "The Symbolic Form of Art," more precisely in the third chapter dedicated to the symbolism of the comparative art-form in which the question of metaphors is addressed, Hegel starts his discussion with a very general remark, saying: "Every language already contains a mass of metaphors. They arise from the fact that a word which originally signifies only something sensuous is carried over into the spiritual sphere." ${ }^{27}$ The emphasis is on the "sensuous" element that is "carried over" and not simply discarded, but rather retained and preserved in the "spiritual sphere," which is of course Hegel's usual dialectical procedure of Aufhebung. ${ }^{28}$

The examples given in order to demonstrate that metaphors contain a certain sensorial element that is preserved in their spiritual meaning are fassen and begreifen: words that "relate to knowing, have in respect of their literal meaning a purely sensuous content, which is then lost and exchanged for a spiritual meaning, the original sense being sensuous, the second spiritual."29 Then, a genealogy of metaphorical language is given as if the metaphorical element in the use of such words has slowly disappeared and the word has changed "from a metaphorical to a literal expression," thus forming a three-step development: first, we have plain words denoting mere sensuous content, then metaphors arise from this sensuous content pointing towards something other than their original meaning, and in the last instance, we have a literal expression that articulates a purely spiritual content without any sensorial meaning. ${ }^{30}$

27 Hegel, 403.

28 Nancy points out in his The Speculative Remark (One of Hegel's Bons Mots), trans. Céline Suprenant (Stanford: Stanford University Press, 2001), that there is no distinctively Hegelian dialectics without the concept of Aufhebung, which means both "abolition" and "preservation," thus enabling the dialectical progression from content to content; however, despite the fact that in the last instance, anything can be aufgehoben, there is at least one concept that cannot be, and that is the concept of Aufhebung itself.

29 Hegel, Aesthetics: Lectures on Fine Art, 404.

30 Hegel's procedure here is the same as at the very beginning of Phenomenology of Spirit, trans. Arnold V. Miller with an analysis of the text by John N. Findlay (Oxford: Oxford University Press, 1977), 33-38 (“A. Consciousness. I. Certainty at the Level of Sense-Experience-The 'This,' and 'Meaning”'), 
Our point of interest is the reason why the word changes from a metaphorical to a literal expression: because "owing to readiness to grasp in the image only the meaning, image and meaning are no longer distinguished and the image directly affords only the abstract meaning itself instead of a concrete picture." It is no coincidence that the verb used in the "readiness to grasp in the image only the meaning" is the same as in the example that follows; namely, begreifen: "If, for example, we are to take begreifen in a spiritual sense, then it does not occur to us at all to think of a perceptible grasping by the hand." It is as if by grasping the meaning inside the image, it is already employing an implicitly metaphorical use of the concept of $B e$ griff. ${ }^{31}$ Language as such, not just the language of metaphysics, therefore has an inherently dialectical tendency towards pure meaning, understood as a source of clarity and certainty. In order to purify itself from any physical residuum and the related doubtfulness of the senses, it needs metaphors as an intermediate step from the sensorial towards the spiritual. And this pertains not only to Hegel's own dialectical procedure, but also to metaphysical philosophy, from which doubt takes its ammunition, and, in the last instance, to language itself.

Thus, speaking in strict Hegelian terms, one could say that touch is aufgehoben, dismissed on a physical level as a sense among senses, and at the same time preserved as a metaphor inside the very core of the metaphysical concept par excellence, Begriff. Begriff paradoxically designates not only touch ("handling," "grasping"), but concept itself (“conception," "naming”). Hegel's dialectics therefore implicitly presupposes a specific and paradoxical way of classifying touch: as a sensory experience, it must not only be discarded as a source of doubt and falsehood, but additionally enshrined as the truth inherent to the very concept of conception-including doubt-thus implying a certain sensorial, even tactile quality of language that can, however, be grasped only speculatively through the two contradictory meanings of Begriff.

Begriff therefore allows us not only to think both the conceptual and bodily activity of touching at the same time, but also to speculatively elevate touch-previously understood only as a mere object of doubt-to the same level as doubt, which itself can now quite literally touch us.

\section{A Knot of Touch and Doubt}

After all these dialectical roundabouts, we can now relax and conclude with Lacan's seminar on the sinthome, where one can find the very concept of Begriff employed

where the sensorial is retroactively turned into the conceptual: the sensorial can be the basis for the metaphorical, and the metaphorical in turn for the conceptual, since the very origin is already contaminated with the conceptual.

31 Hegel, Aesthetics: Lectures on Fine Art, 404-5. 
twice in two fairly similar contexts that are both, as we shall see in a moment, connected to our topic of touch and doubt.

One occasion when Lacan employed Begriff was during a lecture in which he raised a particular doubt: Was Joyce mad? While introducing the concept of objet petit a ("object little a")-a hole in the symbolic order, a residuum of the real that cannot be represented in the register of the imaginary (or the register of bodily experiences, for that matter ${ }^{32}$-Lacan explicitly states that it "is $o b$, an obstacle to the expansion of the concrete, namely, encompassing imaginary. Conceivable, namely, graspable by hand. This is the notion of Begriff, graspable in the way a weapon is," and this weapon is "far from being an extension of the arm," but rather "from the start a weapon for throwing"- "we did not wait for cannonballs to throw a boomerang." 33 As we can see, Lacan is well aware of the double meaning of Begriff with which Hegel also toyed; namely, that of simultaneously conceiving and grasping. Moreover, he employs Begriff as touch-concept in the context of discussing the object $a$ as the border of the phenomenological imaginary, itself the primary topic of doubt. And if we know that the "object a" is defined as the object-reason-of-desire, then one is compelled to ask: What is the specific desire crawling behind doubt, and what kind of object motivates it?

For the answer, let us turn to Lacan's theory of knots. If understood as a visualisation of his famous RSI scheme (real-symbolic-imaginary), the theory of knots looks like a regression to the imaginary register that his earlier arithmetisations tried to undo precisely in order to provide scientific validity to the deceiving imaginary of the senses and their body, which is otherwise understood as the primal object of doubt. ${ }^{34}$ On the other hand, as Milner brilliantly pointed out on more than one

32 The object $a$ has a long conceptual history in psychoanalysis: its origins can be found in Freud's conception of the "lost object," which he discovered while writing his Three Essays on the Theory of Sexuality and which was popularised by Karl Abraham under the title of "partial object"; the concept was then taken up by Melanie Klein, who put it at the very centre of her theory of sexuality, and through her by Donald Winnicott, who renamed it the "transitional object"; finally, Lacan rebaptised it as objet petit $a$ in his seminars delivered as early as the late 1950s, and it underwent many redevelopments until the late 1960s (see Jacques-Alain Miller, "Microscopia: An Introduction to the Reading of Television," trans. Bruce Fink, in Jacques Lacan, Television; A Challenge to the Psychoanalytic Establishment, ed. Joan Copjec, trans. Denis Hollier, Rosalind Krauss, Annette Michelson, and Jeffrey Mehlman [New York: W.W. Norton \& Company, 1990]: xi-xxxi).

33 Lacan, Séminaire, livre XXIII: Le sinthome, 86.

34 Lacan argued that it is the symbolic order that linguistically structures the imaginary as exemplified by the visual or scopic field in his The Four Fundamental Concepts of Psychoanalysis, where the "object a" is identified with the gaze: the logic of the signifier, as developed in this stage, means that language necessarily has certain imaginary connotations-uttering "body," for instance, invokes the image of a body-while the imaginary itself is rooted in the subject's own body, or rather, in the image of the body, and that is why the intervention of the signifier is needed in order to displace the imaginary fixations of the subject to his or her own body, as well as the body of the other (see Jacques Lacan, Le séminaire, livre XI: Les quatre concepts fondamentaux de la psychoanalyse, 1964, ed. Jacques-Alain Miller [Paris: Éditions de Seuil, 1973]). 
occasion, Lacanian structural psychoanalysis is the scientific heir of the earlier modern Galilean revolution and its replacement of physical space with Euclidean geometric space, and therefore, the theory of knots should be regarded as the logical consequence of the development of Lacan's thought. ${ }^{35}$ Similarly, touch as a bodily and physical experience, if it is to be conceived in the scientific milieu of structuralism, must be displaced into a geometric space and conceived accordingly-and one of the best ways to define touch geometrically is, at least to my mind, through the topology of knots. And now, to answer the question proposed above: the desire behind doubt is, at least in this case, the desire to shatter the bodily imaginary through a scientific geometricisation of space.

This could very well be understood as a continuation of Plato's project, as discussed above. In the very first lecture dedicated to the logical use of the sinthome, we find Lacan's second usage of Begriff precisely in the context of our old and age-old mind-and-body problem:

More geometrico, due to the form so dear to Plato, the individual presents himself as [...] a body. And this body has a power of captivation which is such that to a certain extent it is the blind one should envy. How could a blind man, if he can manage braille, read Euclid? The astonishing thing is that form gives nothing but the sack, or, if you like, the bubble. ${ }^{36}$

To be sure, braille is a system of writing for the blind and visually impaired that itself already implies a certain haptolinguistic quality, since with braille, a tactile language can be distinguished that has no conceptual equivalent inside the traditional linguistic understanding of language in its spoken and written form. ${ }^{37}$ Moreover, braille provides not only tactile certainty to counteract doubt that arises from blindness or impaired vision, but also the metaphysical certainty that is provided by language itself, thus, again, embodying Begriff to the letter (being at the same time linguistically conceptual, as language, and bodily tangible, as writing).

Lacan presents the body as a sack that inflates and deflates itself, moving in binary successions from 0 to 1 , from the absence of a signifier to the presence of one. Accordingly, the signifier does not constitute one, but it indexes the body as an

35 See Milner, Le périple structural.

36 Lacan, Séminaire, livre XXIII: Le sinthome, 86.

37 As I have argued elsewhere where I proposed the coinage of haptem (see Komel, "The Wave of the Sign"), language is defined by Saussurian linguistics as a system of differences where a sign can have meaning only in relation to other signs, and this relational understanding of the sign is what is usually understood as structure. From this perspective, phonemes and graphemes function as minimal material differentiating units without meaning in themselves, but are nevertheless capable of producing meaning in their mutual interaction. The difference of the sign is, in short, analytically reducible to the difference between various phonemes and graphemes, and the haptem similarly functions as a minimal material differentiating unit in language that is, however, grounded neither in any acoustic nor in any visual representation, but rather in the tactility of language, which is best exemplified by braille. 
empty sack that is unable to contain anything: "An empty sack is nonetheless a sack, albeit one which can only be imagined as a skin in terms of the existence and consistence of the body." Both the existence and the consistence of the body are "to be held as real," since it is the real that "holds them-thus the word Begriff which means precisely that." 38 Although Lacan does not mention Hegel, we can clearly see how he employs a similar logic by redoubling the French tenir, used to translate Begriff: Cette existence et cette consistence, il faut les tenir pour réelles, puisque le réel, c'est de les tenir. Thus, the existence and consistence of the body-its imaginary quality-should not be understood in the vulgar materialistic sense of anything substantial or carnal, but rather as a lack or sack, imagined as skin in terms of existence and consistence, both held to be real because it is the real that holds them. This tautological definition is already implied, if we recall, in Hegel's logic of the idea as concept and its realisation, a logic that we can now develop a step further: the idea is real because the real holds up or touches (Begriff, tenir) the reality of its own realisation.

However, in Lacan's dealing with the body as an empty sack, we are still moving within the register of the imaginary (the object of doubt stricto senso), which "demonstrates here its homogeneity with the real," and he adds that "this homogeneity only holds because the number is binary, 1 or 0 ; that is, it only figures 2 because 1 is not 0 , because it exists at zero but does not consist in it," thus introducing a difference between existence and consistence (the 1 has existence in the 0 , but is not consistent in it). Moreover, one can very well redouble the logic of 0 and 1 ad infinitum, thus making a set of such doubles, but in this case, the set makes a third, and this is why "the symbol falling back into the imaginary has the index 2," denoting any given battery of signifiers. And now that the logic of the signifier has been introduced, Lacan redefines the symbol, understood in antiquity as a broken fragment, through Saussure's conception of the sign that we dealt with earlier, implying "the unity and reciprocity of the signifier and the signified," further developing the consequence that "the original signified is without meaning, that it is a mere sign of the choice between two signifiers":

There can be no umpire, as Joyce writes in English, without talking about empire, about the imperium over the body, of which all bear a mark from the beginning. Here the 1 confirms its detachment from the 2.3 can only be reached by an imaginary compulsion, which imposes the idea that the one wishes to interfere with the other, without being linked to anything. ${ }^{39}$

The Borromean knot represents precisely the interrelation of the three rings of the RSI scheme introduced above, defining the three registers of the real, the symbolic, and the imaginary, where a break in any one of them sets the other two free. However, Lacan adds (again in a very Hegelian manner) that "it is not the break between symbolic, imaginary, and real which defines perversion, but the fact that they are al-

38 Lacan, Séminaire, livre XXIII: Le sinthome, 86-87.

39 Lacan, 19. 
ready distinct, and therefore a fourth term must be supposed that happens to be the sinthome." 40 Perversion rests therefore not in the desire to break the Borromean knot, but rather in its very breakability, the fact of its being distinct in three separate rings and therefore the very distinction between the three registers themselves. Perversion, which at first glance appears to be a specificity of the human sexual being, is already inscribed in the theory of the RSI scheme itself; more precisely, in the very distinction between the three registers that implies a fourth, sinthome; sexuality and ontology go, speaking in terms of touch, hand in hand. ${ }^{41}$

In the context of our discussion of touch and doubt, a doubtful touch is perverse inasmuch as the object it is touching is itself a source of doubt, the perversity lying in the attribution of a certain truth to the object; namely, the truth of being false, or at least doubtful. Perversion as a Borromean knot in Lacan's account demonstrates a few more tactile qualities worth lingering on for just a little longer before proceeding to our conclusions. First and foremost, a knot is a knot, defined in mathematics as an embedding of a circle in three-dimensional Euclidean space (R3), a bending of the circle in such a way that it touches upon itself in every given crossing, self-touch of the circle that is, in itself, a non-knot, an unknot, a zero-degree touch. Second, the Borromean knot is, like any mathematical knot, closed, since there are no ends to tie or untie these kinds of knots and therefore they can only be untied if they are forcefullly broken, meaning that their touchability, the touch of their crossing, can be un-touched only through a not-touch. Third, if the Borromean knot embodies the RSI scheme where the perverse breaking of one of the rings is identified with the original distinction between them, implying the fourth element of the sinthome to tie and untie an otherwise closed knot, then touch can be conceived as a sinthome; namely, what ties and breaks the knot.

In short: touch is the tie and the break of the knot, similar to the way in which a line is bent into a circle in such a manner that it touches upon itself, and, at the same time, the break within the knot that sets it free from itself: thus touch, again, occupies both places at once, since it is the source of doubt (the tie) as well as the liberation from it (the break).

\section{Conclusion}

The road has been long and not without its pearls and pitfalls, the former provided mostly by the references employed, the latter by the author of this contribution himself, who has attempted to tie the topic of haptic scepticism-or haptoscepticism-to haptolinguistics, thus redoubling the applied conceptual apparatus in order to devel-

40 Lacan, 10.

41 See Alenka Zupančič's brilliant development of the link between ontology and sexuality as laid out in her book What Is Sex? (Cambridge, MA: MIT Press, 2018). 
op the main thesis that promised to provide a linguistic turn of the concepts of both touch and doubt.

The initial juxtaposition of the two scenes from the New Testament provided us with two apparently contradictive conceptions of touch and doubt: in the Mary Magdalene scene, touch is dismissed as a source of doubt, while language, embodied in noli me tangere, provided its counterpart, the certainty of faith, whereas in the Doubting Thomas scene, touch functions as a source of empirical certainty that has to supply not only what the subjects sees and hears-that is, the resurrected body of Christ -but also, and more importantly, the meaning of his words, with touch thus functioning as a supplement to language.

In order to answer the question of how is it possible that touch can play two such different roles, we turned first to Plato, who provided us-with conceptual help from Lacan, Derrida, Nancy, Saussure, and others-with a first approximation of an answer: touch as a metaphor, or the metaphor of touch, allows a free metonymical transitioning between the realm of intangible ideas, identified with the linguistic level of signifiers, and that of tangible bodies, broadly coinciding with the level of the signified. In the second stage, Hegel and his theory of metaphors and language provided us with the concept of Begriff, the concept of "concept" and "touch" in their speculative unity: as a sensory experience, touch must not only be discarded as a source of doubt, but also enthroned as the certain truth inherent in the very concept of conception, thus implying a certain sensorial, even tactile quality of language which, furthermore, also pertains to doubt, touching upon us at the same time that it relinquishes touch as a bodily experience. Last but not least, Lacan's theory of knots provided us with the appropriate conceptual apparatus for the task of further defining this specific haptolinguistic quality of doubt that was, in final analysis, defined as a sinthome, or the perverse moment inherent in any simple scientific attempt at a symbolic dissolution of the imaginary, bodily, sensory experience of touching.

Thus, following this thread that goes from Plato to Lacan, we can see that the real perversion lies not in any simple sexual touching that arouses the subject and raises doubt, but rather in the very fundamental ontological conception that tries to (un)tie touch as the real, doubt and language as the symbolic, and the body as the imaginary phenomenological experience.

\section{Bibliography}

Aristotle. Complete Works. Edited by Jonathan Barnes. 2 vols. Princeton: Princeton University Press, 1984.

Aumiller, Rachel. "The Lick of the Mother Tongue: Derrida's Fantasies of 'the Touch of Language' with Augustine and Marx." In The Language of Touch: Philosophical Examinations in Linguistics and Haptic Studies, edited by Mirt Komel, 107-20. London: Bloomsbury, 2019.

Derrida, Jacques. Le toucher-Jean-Luc Nancy. Paris: Galilée, 2000.

Derrida, Jacques. "White Mythology: Metaphor in the Text of Philosophy." In Margins of Philosophy, translated by Alan Bass, 207-71. Chicago: Chicago University Press, 1982. 
Dolar, Mladen. “Touching Ground.” Filozofski vestnik 29, no. 2 (2008): 79-100.

Hegel, Georg Wilhelm Friedrich. Aesthetics: Lectures on Fine Art, Volume One. Translated by T.M. Knox. Paperback ed. Oxford: Clarendon Press, 1988.

Hegel, Georg Wilhelm Friedrich. Frühe Schriften. Volume 1 of Werke. Edited by Eva Moldenhauer and Karl Markus Michel. New ed. Frankfurt am Main: Suhrkamp, 1986.

Hegel, Georg Wilhelm Friedrich. Phenomenology of Spirit. Translated by Arnold V. Miller with an analysis of the text by John N. Findlay. Oxford: Oxford University Press, 1977.

Homer. The Illiad. Translated by Samuel Butler. Clayton, DE: Prestwick House, 2011.

Homer. The Odyssey. Translated by Stephen Mitchell. New York: Atria Books, 2013.

Kolenc, Bara. "The Category of the (Un)Touchable in Haptic Materialism: Touch, Repetition, and Language." In The Language of Touch: Philosophical Examinations in Linguistics and Haptic Studies, edited by Mirt Komel, 91-106. London: Bloomsbury, 2019.

Komel, Mirt. "The Wave of the Sign: Pyramidal Sign, Haptic Hieroglyphs, and the Touch of Language." In The Language of Touch: Philosophical Examinations in Linguistics and Haptic Studies, edited by Mirt Komel, 5-18. London: Bloomsbury, 2019.

Lacan, Jacques. Écrits. Paris: Éditions de Seuil, 1966.

Lacan, Jacques. Le séminaire, livre XI: Les quatre concepts fondamentaux de la psychoanalyse, 1964. Edited by Jacques-Alain Miller. Paris: Éditions de Seuil, 1973.

Lacan, Jacques. Le séminaire, livre XXIII: Le sinthome, 1975-76. Edited by Jacques-Alain Miller. Paris: Éditions de Seuil, 2005.

Merleau-Ponty, Maurice. Phenomenology of Perception. Translated by Colin Smith. New ed. New York and London: Routledge, 2002.

Merleau-Ponty, Maurice. The Visible and the Invisible; Working Notes. Edited by Claude Lefort. Translated by Alphonso Lingis. Evanston, IL: Northwestern University Press, 1968.

Miller, Jacques-Alain. "Microscopia: An Introduction to the Reading of Television." Translated by Bruce Fink. In Jacques Lacan, Television; A Challenge to the Psychoanalytic Establishment, edited by Joan Copjec, translated by Denis Hollier, Rosalind Krauss, Annette Michelson, and Jeffrey Mehlman, xi-xxxi. New York: W.W. Norton \& Company, 1990.

Milner, Jean-Claude. Le périple structural: Figures et paradigme. Paris: Éditions du Seuil, 2002.

Morris, Charles. Paths of Life: Preface to a World Religion. New York: Harper and Brothers, 1942.

Nancy, Jean-Luc. Noli me tangere: Essai sur la levée du corps. Paris: Bayard, 2003.

Nancy, Jean-Luc. The Speculative Remark (One of Hegel's Bon Mots). Translated by Céline Surprenant. Stanford: Stanford University Press, 2001.

Pepper, Stephen C. World Hypotheses: A Study in Evidence. Berkeley: California University Press, 1942.

Plato. Complete Works. Edited by John S. Cooper. Indianapolis and Cambridge: Hackett, 1997.

Saussure, Ferdinand de. Course in General Linguistics. Edited by Charles Bally and Albert Sechehaye in collaboration with Albert Riedlinger. Translated by Wade Baskin. 3rd ed. New York, Toronto, and London: McGraw-Hill, 1966.

Sophocles. The Three Theban Plays. Translated by Robert Fagles. London: Penguin Classics, 2008. Zupančič, Alenka. What Is Sex? Cambridge, MA: MIT Press, 2008. 